\title{
Urban Morphology Promotes Urban Vibrancy from the Spatiotemporal and Synergetic Perspectives: A Case Study Using Multisource Data in Shenzhen, China
}

\author{
Sijia $\mathrm{Li}^{1}$, Chao $\mathrm{Wu}^{2}, \mathrm{Yu} \mathrm{Lin}{ }^{3}$, Zhengyang $\mathrm{Li}^{4}$ and Qingyun $\mathrm{Du}^{1,5,6,7, * \mathbb{C}}$ \\ 1 School of Resources and Environmental Sciences, Wuhan University, 129 Luoyu Road, Wuhan 430079, China; \\ sjliwhu@gmail.com \\ 2 School of Geographic and Biologic Information, Nanjing University of Posts and Telecommunications, \\ Nanjing 210023, China; chaowu@njupt.edu.cn \\ 3 Hubei Institute of Land Surveying and Mapping, 199 Aomen Road, Wuhan 430010, China; \\ linyu_whu@163.com \\ 4 Yunnan Provincial Mapping Institute, 223 Xichang Road, Kunming 650034, China; \\ zhengyangli822@foxmail.com \\ 5 Key Laboratory of Geographic Information System, Ministry of Education, Wuhan University, \\ 129 Luoyu Road, Wuhan 430079, China \\ 6 Key Laboratory of Digital Mapping and Land Information Application Engineering, Ministry of Natural \\ Resources, Wuhan University, Wuhan 430079, China \\ 7 Collaborative Innovation Center of Geospatial Technology, Wuhan University, Wuhan 430079, China \\ * Correspondence: qydu@whu.edu.cn
}

Received: 15 April 2020; Accepted: 9 June 2020; Published: 12 June 2020

\begin{abstract}
Urban vibrancy is the key and the foundation for monitoring the status of urban spatial development, assisting in data-driven urban development planning and realizing sustainable urban development. Based on a dataset of multisource geographical big data, the understanding and analysis of urban vibrancy can be deepened with fine granularity. The working framework in this study focuses on the comprehensive perspective of urban morphology, which is decomposed into two dimensions (formality and functionality) and four elements (road, block, building, point of interest). The geographically and temporally weighted regression model was first applied to determine the spatiotemporal effect of the morphological metrics on vibrancy, and then, the geographical detector was employed from the perspective of spatially stratified heterogeneity to reveal the synergetic impacts. The following findings were revealed. (1) Dense street networks, small and medium-sized blocks, and the diversification and intensification of building and land use are beneficial to urban vibrancy. (2) Under the premise of adapting to local conditions, urban spaces combine multiple morphological metrics for the accomplishment of a full-region and all-time vibrancy. (3) The mixture of urban functions is worthy of attention for vibrancy growth because of its extraordinary synergy, not its capacity. Morphological metrics serve to foster and prolong urban vibrancy, adapt to urban sustainability, and contend against inefficient, disorderly urban sprawl. These findings provide significant implications for urban planners/designers and policymakers to optimize urban morphology, improve the vibrancy in large cities, and implement high-quality city planning.
\end{abstract}

Keywords: urban vibrancy; urban morphology; spatiotemporal effect; synergetic effect; multisource data 


\section{Introduction}

\subsection{Background}

The urban population comprises $55 \%$ ( 4.2 billion) of the global population and is projected to reach $68 \%$ ( 6.7 billion) by 2050 [1]. The world shares the concern for the maximization of the benefits of population aggregation and the simultaneous minimization of environmental degradation and other potential adverse consequences of the growing urban population. Sustainable urbanization in the economic, social, and environmental spheres is key to successful urban development [2]. Urban vibrancy, innovation, and resilience profoundly affect city sustainability. Urban vibrancy acts as a cornerstone for the other two elements: a livable and vibrant city provides people with a good emotional experience and psychological feelings associated with urban space, which is crucial for their innovation or creativity [3,4]. Vibrancy offers cities resilience and prosperity, enabling them to cope with adverse internal and external events [5].

Urban vibrancy is the driving force for comprehensive, coordinated, and sustainable urban development [6]. Recognizing the critical need to create, maintain, and advance urban vibrancy, municipal authorities increasingly adopt urban vibrancy as an organizing concept for guiding planning and governing. Although scholars have proposed various definitions of urban vibrancy $[7,8]$, the term inherently entails attempts to satisfy human daily needs and social public demands and create a livable environment. The organizing concept of urban vibrancy advocates the creation of neighborhoods with good urban morphology, complete urban functions, and plentiful urban activities [8] and the maximization of urban developments around communities. Currently, new urbanism and smart growth are the inherited concepts being developed from the theory of urban vibrancy to counter inefficient, disorderly urban sprawl.

Urban vibrancy is accompanied by a diversity of benefits, such as equalizing the spatial layout of local facilities, shaping polycentric urban regions, promoting strong connections among social interactions, improving the quality of urban life, attracting talent and capital, and enhancing economic competitiveness [9-12]. In the absence of vibrancy, a series of social issues, including economic stagnation, land waste, and brain drain and capital flight, become serious impediments to the healthy and orderly development of cities [13]. Theorists and practitioners have explored and elucidated that urban morphology is one of the effective paths for intervening in urban systems and guiding urban development $[14,15]$. To allow urban morphology to fully play a role in vibrancy in local improvement and overall promotion, it is necessary to examine the individual spatiotemporal effect and interactive effect of urban morphology on vibrancy.

One of the most prominent characteristics of urban vibrancy is that the amount of people or the accumulated amount of people varies across periods and places [3,7]. Correspondingly, the spatiotemporal effect of urban morphology on vibrancy is the spatiotemporal potential of residents interacting in and occupying the urban space when engaged in different activities at different times of the day $[4,16,17]$. Urban morphology is composed of multiple interrelated and interdependent elements (e.g., roads and blocks, or plots and buildings) $[18,19]$. Accordingly, the interactive effect of urban morphology on urban vibrancy concerns the conglomeration and integration of two or more individual elements. However, little research has demonstrated the spatiotemporal effect and synergetic effect of urban morphology on vibrancy. Hence, we attempt to address the above knowledge gaps in this study.

\subsection{Literature Review}

\subsubsection{Urban Vibrancy}

Jacobs, one of most influential urban sociologists, first conceptualized urban vibrancy as the "rich diversity of urban life" consisting of interactions among residents and between residents and their production and living place [7]. Lynch defined urban vibrancy as the potential of a city to 
"support the vital functions, biological requirements and capabilities of human beings and protect the continuation of the species" [8]. Maas suggested urban vibrancy as having three components: "people, their activities and opportunities, and the environment where activities occur" [20]. Montgomery considered urban vibrancy an integrated representation of the "many and varied comings and goings, meetings and transactions" [3]. Some researchers developed a composite index to describe urban vibrancy, reflecting compactness, density, regional and local connectivity, destination accessibility, land use mix, and social diversity [21-25]. City authorities also proposed a variety of definitions of urban vibrancy. Although no definition of urban vibrancy is uniformly accepted among scholars and authorities, the common foundation of urban vibrancy remains the organic and indivisible connection and communication between urban entities, including people, which is externally manifested by dynamic changes in the dispersion and concentration of activities in the spatial dimension and the continuity and fluctuation of activities in the temporal dimension. Internal characteristics typically feature small-to-moderate blocks with dense street networks, diverse and intense construction, and multilevel/multiple city configurations.

According to such a prominent representation, the measurement of urban vibrancy can be transferred into the assessment of the intensity of human activities in urban space. The shortcomings of traditional data derived from censuses and surveys are their low resolution, small sample sizes, and high collection costs. The boom in information and communication technologies has created the possibility of obtaining accurate and tremendous data on residents' daily activities. The newly available spatiotemporal big data provide significant advantages for the study of the dynamics of urban vibrancy at an unprecedentedly fine spatiotemporal scale. To date, various sources of big data have been employed as proxies of urban vibrancy. The most common proxy of urban vibrancy is mobile phone data, which directly reflect the distribution of activity intensity in urban space [10,26-28]. Other location-based service (LBS) data sources, reflecting specific aspects of urban spatiotemporal vibrancy, are also used as approximations of urban vibrancy, including social media data, public transport smartcard data, taxi data, shared bike data, and Wi-Fi access point data [29-32].

Compared with traditional and static statistical sources, these spatiotemporal big data sources have greater spatiotemporal granularity, enabling research on details of the spatiotemporal variability in urban vibrancy. Due to the high penetration rate and carry-on usage of mobile phones, mobile phone data, especially mobile phone positioning data, offer valuable opportunities to study the social interactions and travel behaviors of the whole population. Four of Jane Jacob's principles, including dense concentrations of office workers, third places at walking distance, small streets, and aged buildings, about vibrant cities were quantitatively affirmed based on mobile phone data in six cities in Italy [26]. User activity records contained in LBS data and supplemental data have been applied to assess the vibrancy of urban residential developments throughout China [10]. Due to the advantages of comprehensive population coverage, continuous temporal coverage, accurate spatial coverage, and high unit granularity, we utilized mobile phone positioning data to represent the temporal and spatial variances in urban vibrancy.

\subsubsection{Urban Morphology and Vibrancy}

Urban morphology terminologically depicts the urban environment, or the conformation of the whole fabric of a city. More specifically, urban morphology includes the pattern and representation of not only the tangible physical environment but also intangible human activities across time and space. The city is an organic whole composed of a group of morphological elements, which can be recognized and interpreted at different resolutions. Urban morphology at the mesoscale, which is of concern in this paper, focuses on the structure and layout of streets, blocks, plots, and buildings [18,33,34]. As shown in Figure 1, the constituent elements of urban morphology are intertwined and interrelated. Streets form the framework of urban space and divide the city into large and small blocks. Blocks internally configure a series of plots with different shapes and functions. Plots arrange buildings (e.g., commerce, office, education, transport) and open places (e.g., squares, parks, courtyards) of all ages and uses. 
Streets, blocks, plots and buildings are integrated in a particular way, forming different patterns in each region in the city (Figure 2). Scholars supported the view that all elements of urban morphology are interrelated, interactive, and inseparable $[24,35,36]$. However, there are no empirical studies to verify the synergetic effect; in other words, the combined effect of the morphological elements on vibrancy could be greater than its individual parts.

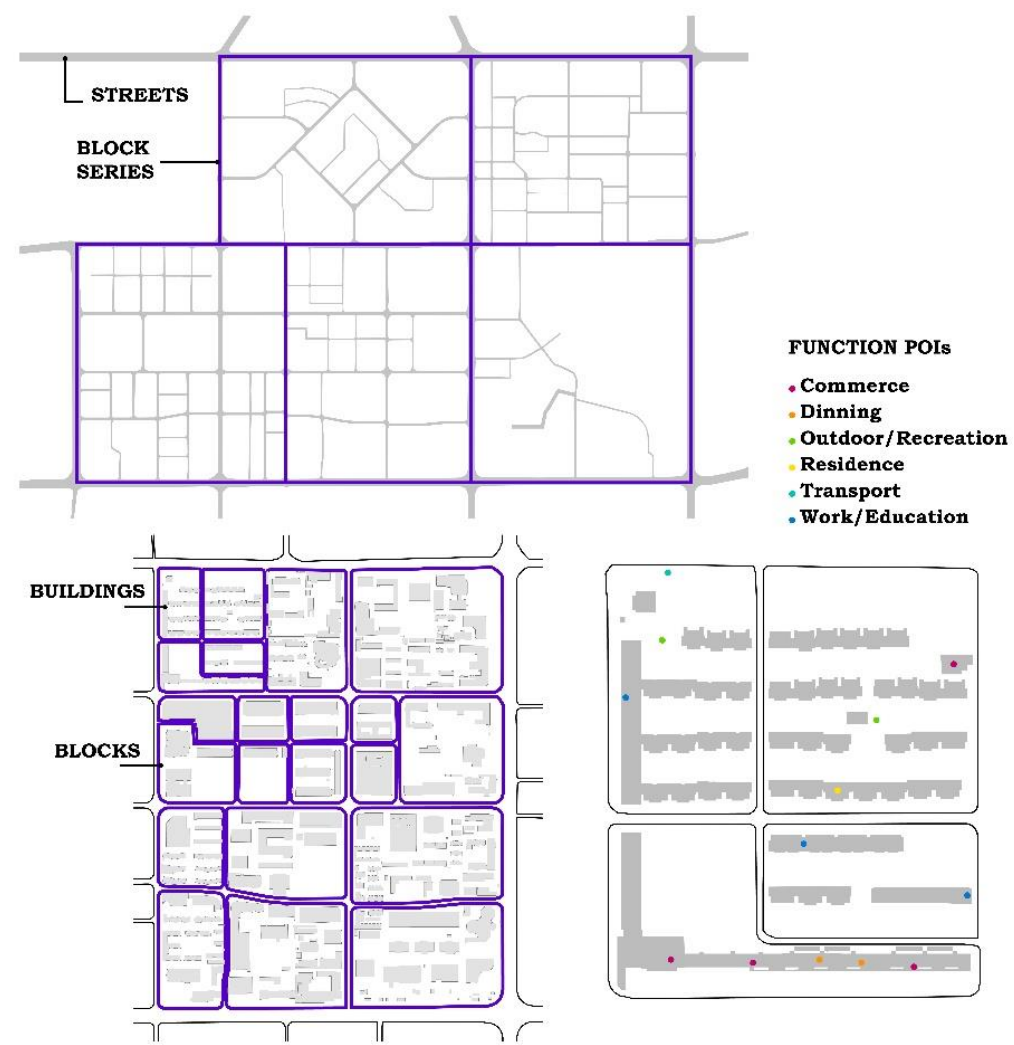

Figure 1. Constituent elements of urban morphology at the mesoscale.
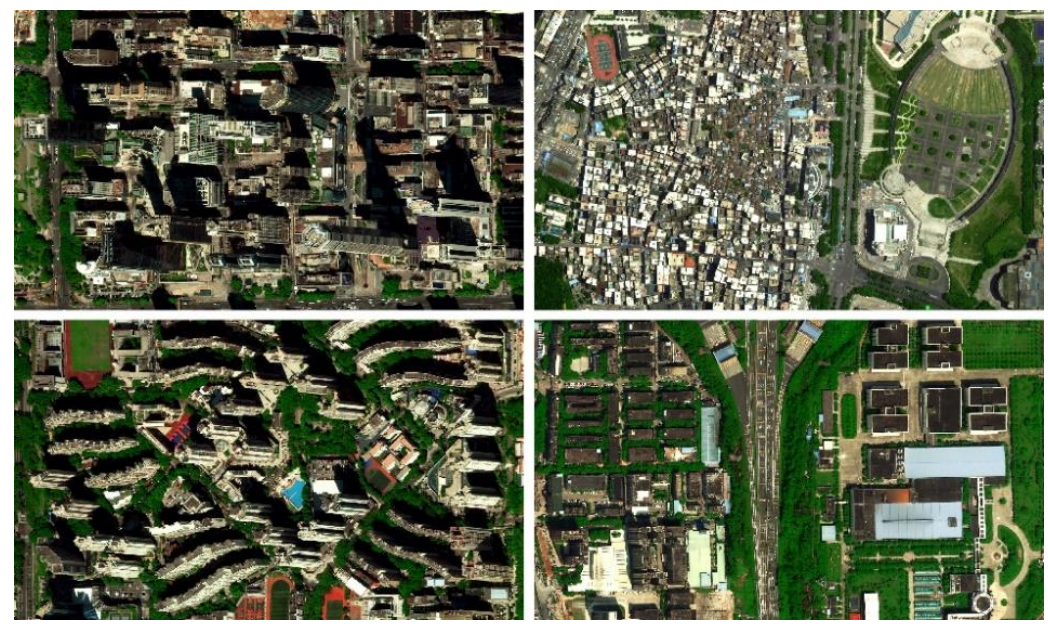

Figure 2. Different urban tissues in Shenzhen, approximately at the same scale: Huaqiangbei, Shajing, Baihua, and Qinghu (Source: Tencent Street View).

The academic and professional communities have demonstrated much interest in the significant contributions of urban morphology to urban vibrancy [29]. Early scholars concentrated on theoretical research. Katz listed the important factors of urban vibrancy: compactness, walkability, mixed function, and appropriate building density [37]. Gehl posited that mixed function, slow traffic, and open 
blocks influence urban vibrancy [38]. Following the constituent elements of urban morphology, case-specific indices have been developed to decipher and deconstruct urban vibrancy at the mesoscale. Typical examples of application include Toronto in Canada [39], Tokyo in Japan and New York in the U.S. [40], Ontario in Canada [41], Seoul in South Korea [42], Tehran in Iran [17,43], Chicago in the U.S. and Wuhan in China [44], Oslo in Norway [45], Beijing in China [28], and Barcelona in Spain [46].

Xia et al. noted the similar local patterns between land use density/intensity and urban vibrancy in Chinese five city [47]. Zeng et al. decomposed the vibrancy of Chicago and Wuhan into four aspects: density, accessibility, livability, and diversity [44]. At the mesoscale, some vigorous morphological characteristics are generally recognized in the above studies: dense street networks, small and medium blocks, and diversification and intensification of building and land use. The first three are formal, and the last one is functional.

The ordinary least squares (OLS) regression model, as the most representative and widespread approach among statistical methods, was used for comprehending and processing the complicated relationship between urban morphology and vibrancy [28,42]. The basic assumption of the OLS model is that neighborhood-level human activity data are independent and stationary in urban space. Nevertheless, human activity data in a particular place violate the independence hypothesis due to the spatial nonstationarity and spatial dependence among adjacent neighborhoods. Therefore, the OLS approach to urban vibrancy modeling has been noted to have limited validity because it ignores the spatial variation $[28,47]$. Delclòs-Alióa et al. pointed out that different urban morphologies in different regions potentially result in different degrees of urban vibrancy [46]. The spatial nonstationarity lies in the sensitivity of urban vibrancy to urban morphology and geographical location. Spatial nonstationarity among units with different urban vibrancy leads the estimation coefficients of the explanatory variables to vary spatially across different observations. The necessity of incorporating spatial nonstationarity into the regression model for the spatial heterogeneity of urban vibrancy must be emphasized.

Notably, when modeling spatiotemporal data (activity intensity) using OLS, the dependent variable requires being aggregated or averaged by a certain period, the average daily intensity of activity, for example. Time is another crucial dimension that global OLS models cannot capture sufficiently. The limitation is especially evident when analyzing activity intensity in a neighborhood where the difference between day and night, week and weekend cannot be ignored. This demonstrates that activity intensity is also temporally nonstationary. Similar to spatial nonstationarity, temporal nonstationarity denotes that activity intensity is time-sensitive. The spatiotemporal variations of urban vibrancy should be considered [47-49]. Sung et al. discovered that the urban physical environment plays different roles in pedestrian activity at different periods of the day by using household travel survey data and designing an all-day and multi-period methodology [50]. Wu and Niu evaluated the impact of the built environment on urban vibrancy through spatial lag model in six time period [51]. Tang et al. preliminarily revealed the continuum spatiotemporal impact of form elements on urban vitality using geographically and temporally weighted regression but missed some essential elements, such as building density and building height [52]. Prior studies have greatly advanced the knowledge about urban vibrancy, but two issues need to be further deepened. First, minimal research effort has been directed to the spatiotemporal effects of urban morphology on vibrancy from the view of functionality and formality. Second, there is a lack of quantitative studies of the synergetic effects of functionality items and formality items of morphology factors, which may have resulted in incomplete conclusions.

\subsection{The Present Study}

After 40 years of massive and rapid urbanization, China has been obliged to face the dilemma of serious population over-agglomeration problems to achieve a reasonable adaptation and balance of human activities and the urban layout. With the increasing demands for livability, Chinese urban construction has entered into a key era of transformation and upgrade from "incremental expansion" to "inventory optimization," paying attention to the improvement of urban life quality and urban 
sustainability. The advancement of urban vibrancy has been the priority in urban planning, mentioned in the master plans of 60 cities approved so far by the State Council. Urban vibrancy plays a critical role in promoting sustainable urban development. In this context, how to foster urban vibrancy in urban planning and designing practices has been widely discussed among scholars. Among them, urban morphology is regarded as an efficient and effective breakthrough. However, there are challenges for implementing morphogenetic vibrancy within a Chinese context, because the theoretical and practical progress are relatively lagging. Little quantitative research has been conducted to evaluate the spatiotemporal and interactive effects of urban morphology on urban vibrancy variations and provide actionable insights for planning implications. Our work attempts to close the knowledge gap and selects Shenzhen as the study area.

Shenzhen is one of the earliest urbanized, fastest urbanizing, and most urbanized metropolises in China. It is located in the coastal area of the South China Sea and is on the northern border of Hong Kong (Figure 3). The total area of Shenzhen is $1997.47 \mathrm{~km}^{2}$, and the city has ten administrative districts. South Shenzhen contains the downtown, as well as the financial district (Futian) and the earliest developed and most mature commercial district (Luohu) and high-technology zones (Nanshan). North Shenzhen, including Baoan, Guangming, Longhua, Longgang, Pingshan, is an advanced manufacturing base. East Shenzhen has an international port (Yantian) and a natural reserve area (Dapeng) with country parks and beaches. The Traffic Analysis Zone (TAZ) was adopted as the basic observation unit to conduct neighborhood scale analysis. The focus area of this study contains 976 TAZs, keeping continental TAZs and removing insular TAZs in the bottom left.

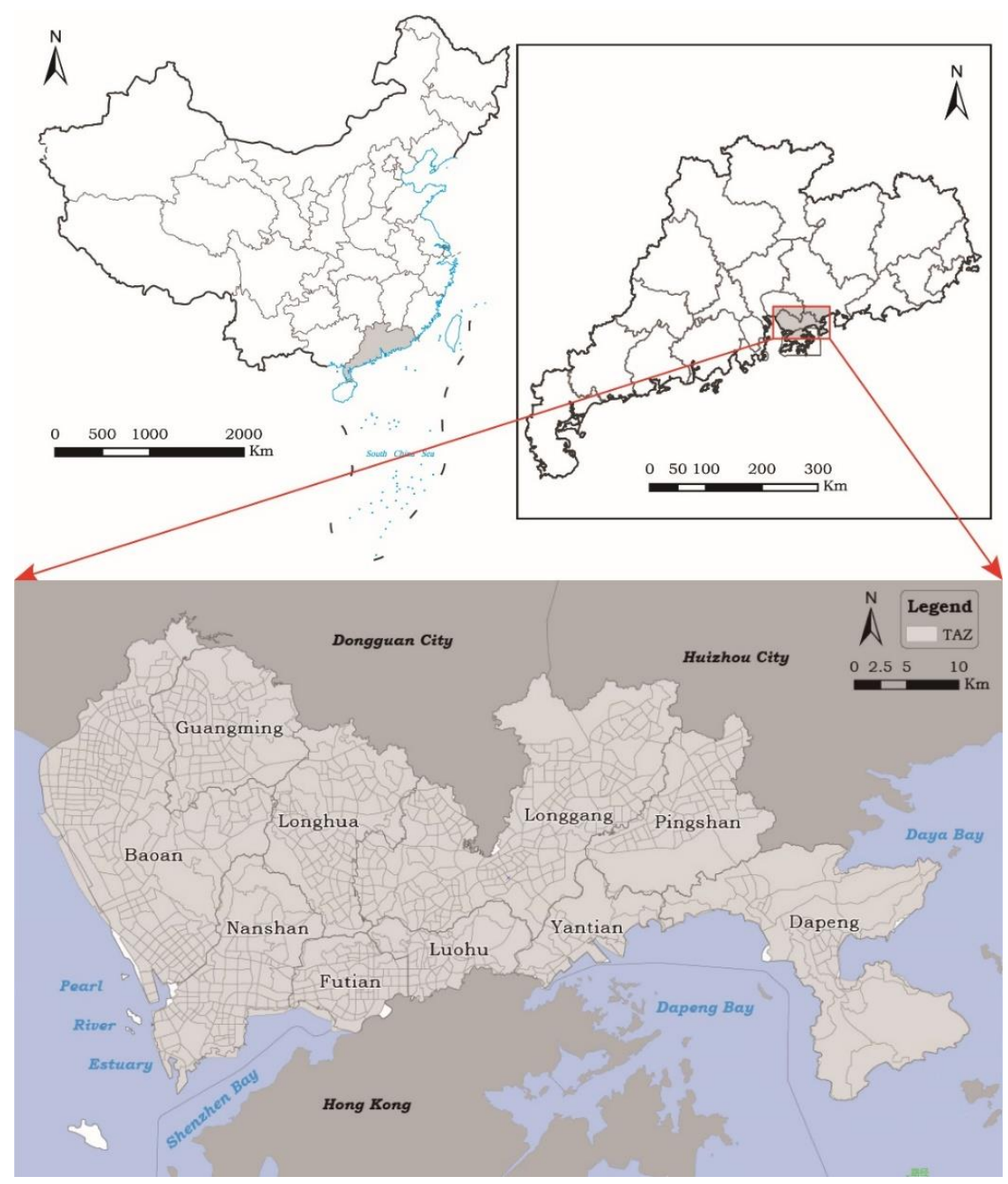

Figure 3. Study area in Shenzhen. 
By the end of 2018, the resident population in Shenzhen had reached 13.03 million, among which 4.55 million were registered permanent residents. The GDP of Shenzhen increased to 2422.20 billion RMB in 2018, ranking fifth among Asian cities. Since it was established in 1979, along with becoming the first Special Economic Zone of China in the same year, Shenzhen has evolved into a dynamic and energetic hub of high-tech innovation, trade and logistics, and economy at an unprecedented pace. In particular, the Master Plan has introduced the urban vibrancy concept into high-quality design at fine scales and adopted urban vibrancy as a pivotal element of sustainable urban development. Examining the effect of urban morphology on the urban vibrancy of Shenzhen provides an adequate basis for exploring the form patterns, functional configurations, and dynamic interactions in China.

Focusing on the urban vibrancy from mobile phone positioning data in Shenzhen, this paper analyses how the urban morphology affects urban vibrancy at the neighborhood level. Our specific objectives were to (1) develop a reasonable metric system involving formality and functionality, (2) apply an explicit approach to explore the temporal and spatial effects of urban morphology on vibrancy variations, (3) leverage a novel approach to detect the synergy of urban morphology on vibrancy, and (4) provide implications for urban vibrancy in local improvement and overall promotion.

\section{Data}

\subsection{Mobile Phone Data}

Large quantities of information on the daily activities of city dwellers are collected by a mobile communication system, recording positioning data every $15 \mathrm{~min}$ for mobile phone users. We used two months of mobile phone positioning data, from 1 May 2016 to 30 June 2016, with 426 million records on an average day. Only the location and time attributes of each record in the mobile communication database are extracted to protect users' privacy. Aggregating mobile phone positioning data by swiping time and TAZ-ID can allow the mapping of digital communication device records in a spatiotemporal context where the variability of urban vibrancy is explored in the spatiotemporal dimension. In our work, the average hourly activity intensity was considered separately for weekdays and weekends to evaluate the differences. Figure 4 shows urban vibrancy at the TAZ level during two months, covering the hourly averages of TAZ vibrancy on weekdays and weekends. Regarding the two graphs, there are distinct differences among different TAZs hourly and daily. There are clear distinctions between day and night for urban vibrancy on weekdays: TAZ A has high vibrancy during the day and low vibrancy at night; TAZ B is the opposite. Urban vibrancy on weekends has a greater number of persistent highlights, TAZ B is vibrant all day on weekends.

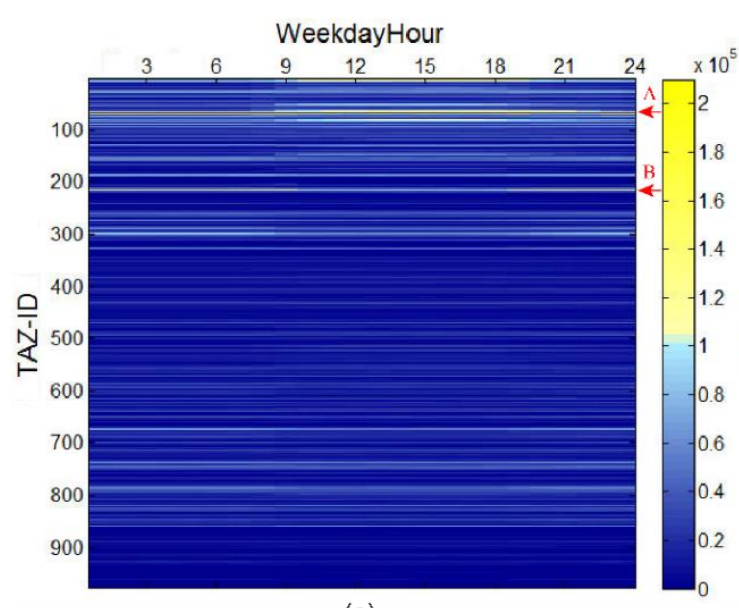

(a)

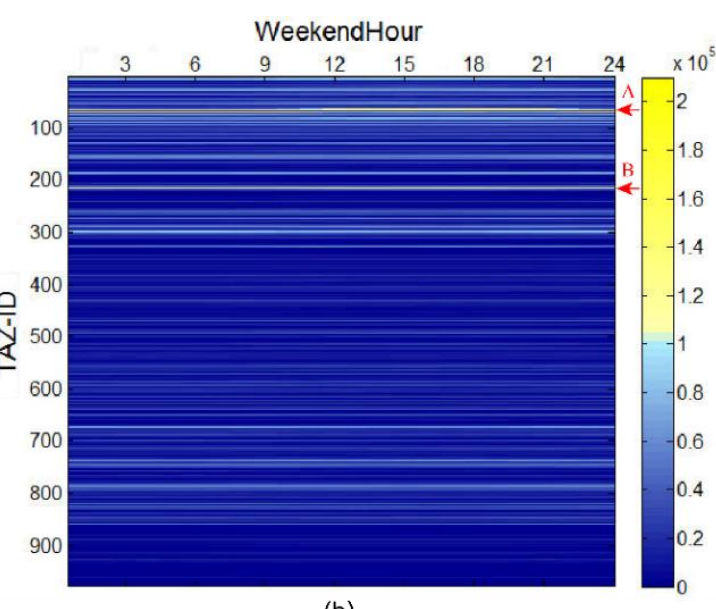

(b)

Figure 4. Urban vibrancy at the Traffic Analysis Zone (TAZ) level: (a) WeekdayHour; (b) WeekendHour. 


\subsection{Neighborhood Morphological Data}

Morphological data sources include road networks, point of interest (POI) data, building footprints, and building vector data (including building age and building height). Data for the first three were provided by the Shenzhen Municipal Bureau of Planning and Natural Resources. The building vector data, including the attributes of floor height and built age for 6046 dwelling quarters, were crawled from Lianjia (https://www.lianjia.com), Anjuke (https://www.anjuke.com/), and Fangtianxia (https: $/ / w w w . f a n g . c o m /)$. These platforms are the leading and mature real estate agent websites in China and have been used in many research works [53-55]. These auxiliary datasets were employed to calculate the morphological metrics.

\section{Methodology}

\subsection{Proposition of the Formality-Functionality Model}

Scholars have explored a great variety of indices to capture neighborhood morphological characteristics from morphological elements (road, block, building, and POI). As mentioned in Section 2.2, vibrant neighborhoods should have the following morphological characteristics: (1) dense street networks, (2) small and medium-sized blocks, (3) diversification and intensification of building, and (4) diversification and intensification of land use. We clarify these characteristics into two dimensions, namely, formality and functionality, by revisiting pilot studies. The formality-functionality (FormFun) model is adopted to establish the index system with a three-layer hierarchy. On the basis of previous studies and data availability, we selected 12 indices from the two morphological dimensions and four morphological elements. Tables 1 and 2 present a detailed description of the indices.

(1) Road. Good road networks enhance the internal urban mobility of people and goods. Density of road length (DRL) and Integration-Choice (INCH) are employed. Integration-Choice (INCH) is derived from space syntax. Regarding the road network, space syntax abstracts the interconnections between road segments into connection graphs. Then, according to the basic principle of graph theory, topological, geometrical, or distance analysis is carried out, and a series of morphological analysis variables are finally derived [56]. The association between the configuration of the road network and economic activity [57,58], function [59], human movement $[60,61]$ has been studied through space syntax. Shen et al. explored the impact of road centrality (integration and choice) and function centrality on people co-presence [62]. Integration measures the capacity of road segment as a destination to attract incoming mobility; Choice reflects the advantage of road segment as the shortest travel path [63,64]. As Integration and Choice having strong correlation in the TAZ scale, INCH is used. It aggregates Integration, and Choice denotes the potential of road segment as both a destination and a transit. The calculation is carried out in Depthmap and radius $=3 \mathrm{~km}$.

(2) Building. Dense buildings facilitate the sufficient concentration of human activity and the full utilization of land. Moreover, the coexistence of old building and new building increases building diversity, thus increasing attraction for people with various tendencies. Building area ratio (BuAR), Building cover ratio (BuCR), and Mixed building age (MixBuA) are chosen to access building morphology. BuAR represents the development density of the building in the vertical direction. BuCR denotes the development density of the building in the horizontal direction.

(3) Block. Contact opportunities and walk activity tend to occur in medium and small-sized blocks $[7,65]$. For the block size measurements, the Density of block number (DBoN) is calculated. The larger the value of DBoN, the smaller the block.

(4) POI. Mixed land use is the ideal state of urban land use, which stimulates human activities for many different purposes at different times throughout the day. The quantity of POIs reflects the ability of facilities to provide diverse functional services. We selected and classified POI related to urban life: Commerce and service category (CSPOI), Outdoor and recreation category (ORPOI), Residence category (ResPOI), Transport category (TraPOI), Work and education category (WEPOI). 
Table 1. Description of indices for assessing neighborhood morphology.

\begin{tabular}{|c|c|c|c|}
\hline Dimension & Component & Index (Abbreviation) & Explanation of Index/Calculation Method \\
\hline \multirow[t]{6}{*}{$\begin{array}{c}\text { Formal } \\
\text { Characteristics }\end{array}$} & Road & $\begin{array}{l}\text { Density of road length } \\
\text { (DRL) }\end{array}$ & $\begin{array}{l}\text { The total length of roads divided by the area of } \\
\text { each neighborhood. }\end{array}$ \\
\hline & & $\begin{array}{l}\text { Angular integration and } \\
\text { choice of roads (INCH) }\end{array}$ & $\begin{array}{l}\text { Integration is the reciprocal of the mean angular } \\
\text { depth }\left(\operatorname{Dep}_{(i, j)}\right) \text { from segment } i \text { to all the } \\
\text { reachable segments } j \text { within a given radius } r \text {. } \\
\text { Choice is the number of times }\left(n_{j k}\right) \text { that the } \\
\text { focused segment } i \text { has been passed through in the } \\
\text { angular shortest paths from segment } j \text { to } k \text { within } \\
\text { a given radius } r \text {. } \\
\qquad I N_{i}=\frac{\left(N_{i}-1\right)}{\sum_{j} \operatorname{Dep}_{(i, j)}},\left\{\operatorname{dis}_{(i, j)} \leq r\right\} \\
\qquad \mathrm{CH}_{i}=\sum_{k} n_{j k},\left\{d i s_{(i, j)} \leq r ; d i s_{(i, k)} \leq r\right\} \\
I I N C H_{i}=\log \left(C H_{i}+2\right) \times I N_{i}\end{array}$ \\
\hline & Building & $\begin{array}{l}\text { Building area ratio } \\
\qquad(\mathrm{BuAR})\end{array}$ & $\begin{array}{l}\text { The total spatial construction area divided by the } \\
\text { area of the neighborhood; the higher the ratio, } \\
\text { the higher the intensity. }\end{array}$ \\
\hline & & $\begin{array}{l}\text { Building cover ratio } \\
\text { (BuCR) }\end{array}$ & $\begin{array}{l}\text { The total of buildings divided by the area of each } \\
\text { neighborhood; the higher the ratio, the higher } \\
\text { the density. }\end{array}$ \\
\hline & & $\begin{array}{l}\text { Mix building age } \\
\quad(\mathrm{MixBuA})\end{array}$ & $\begin{array}{l}\text { The degree of mixing of building ages using the } \\
\text { entropy equation over } 40 \text { years (1980-), with } \\
\text { every } 5 \text { years as an interval. } \\
\qquad M i x B u A=-\sum_{i=1}^{n} p_{i} \log p_{i} \\
\text { where } n \text { is the number of building age categories, } \\
\text { and the } i \text { th building age category has a relative } \\
\text { proportion of } p_{i} .\end{array}$ \\
\hline & Block & $\begin{array}{l}\text { Density of block number } \\
\text { (DBoN) }\end{array}$ & $\begin{array}{l}\text { The total number of blocks divided by the area of } \\
\text { each neighborhood. }\end{array}$ \\
\hline \multirow[t]{6}{*}{$\begin{array}{l}\text { Functional } \\
\text { Characteristics }\end{array}$} & POI & Mix of POIs (MixPOI) & $\begin{array}{l}\text { The degree of mixing of POIs in } 5 \text { categories } \\
\text { using the entropy equation: } \\
\qquad M i x P O I=-\sum_{i=1}^{n} p_{i} \log _{2} p_{i}\end{array}$ \\
\hline & & $\begin{array}{l}\text { Density of POIs in the } \\
\text { commerce and service } \\
\text { category (CSPOI) }\end{array}$ & $\begin{array}{l}\text { The total number of POIs in the commerce and } \\
\text { service category divided by the area of } \\
\text { each neighborhood. }\end{array}$ \\
\hline & & $\begin{array}{l}\text { Density of POIs in the } \\
\text { outdoor and recreation } \\
\text { category (ORPOI) }\end{array}$ & $\begin{array}{l}\text { The total number of POIs in the outdoor and } \\
\text { recreation category divided by the area of } \\
\text { each neighborhood. }\end{array}$ \\
\hline & & $\begin{array}{l}\text { Density of POIs in the } \\
\text { residence category } \\
\text { (ResPOI) }\end{array}$ & $\begin{array}{l}\text { The total number of POIs in the residence } \\
\text { category divided by the area of } \\
\text { each neighborhood. }\end{array}$ \\
\hline & & $\begin{array}{l}\text { Density of POIs in the } \\
\text { transport category } \\
\text { (TraPOI) }\end{array}$ & $\begin{array}{l}\text { The total number of POIs in the transport } \\
\text { category divided by the area of } \\
\text { each neighborhood. }\end{array}$ \\
\hline & & $\begin{array}{l}\text { Density of POIs in the } \\
\text { work and education } \\
\text { category (WEPOI) }\end{array}$ & $\begin{array}{l}\text { The total number of POIs in the work and } \\
\text { education category divided by the area of } \\
\text { each neighborhood. }\end{array}$ \\
\hline
\end{tabular}


Table 2. Characteristics of morphology indices in neighborhoods.

\begin{tabular}{ccccccc}
\hline \multirow{2}{*}{ Dimension } & Component & Index & Min & Max & Mean & Standard Deviation \\
\hline \multirow{4}{*}{ Formal Characteristics } & \multirow{2}{*}{ Road } & DRL & 0 & 58.32 & 13.17 & 6.47 \\
& \multirow{3}{*}{ Building } & INCH & 0 & 3623.16 & 1089.02 & 706.53 \\
\cline { 2 - 6 } & & BuAR & 0 & 19.1 & 1.5 & 2.6 \\
& & BuCR & 0 & 0.59 & 0.18 & 0.11 \\
& \multirow{2}{*}{ Block } & MixBuA & 0 & 0.84 & 0.18 & 0.25 \\
\hline \multirow{4}{*}{ Functional Characteristics } & DBoN & 0.31 & 50.17 & 11.11 & 6.62 \\
& \multirow{4}{*}{ POI } & MixPOI & 0 & 1.04 & 0.75 & 0.23 \\
& & CSPOI & 0 & 1567.89 & 159.23 & 198.82 \\
& & ORPOI & 0 & 19.72 & 1.13 & 2.11 \\
& & ResPOI & 0 & 341.18 & 28.58 & 43.24 \\
& & TraPOI & 0 & 1695.23 & 67.11 & 102.63 \\
& & WEPOI & 0 & 5751.53 & 175.10 & 409.06 \\
\hline
\end{tabular}

\subsection{Geographically and Temporally Weighted Regression (GTWR)}

The spatiotemporal relationship between urban morphology and vibrancy is determined using the GTWR model. Simultaneously considering both spatial and temporal nonstationarity, GTWR generates a spatiotemporal weight matrix within spatiotemporal distance and measures the local relationship with different TAZs and time [66,67]. The GTWR model established in this study to delineate the spatiotemporal relationship between urban morphology and vibrancy can be expressed as follows:

$$
Y_{i}=\beta_{0}\left(u_{i}, v_{i}, t_{i}\right)+\sum_{k=1}^{d} \beta_{k}\left(u_{i}, v_{i}, t_{i}\right) X_{i k}+\varepsilon_{i}
$$

where the dependent variable $Y_{i}$ is the urban vibrancy for sample $i$; $X_{i k}$ is the $k$ th urban morphology variable; $\varepsilon_{i}$ is the residual error term for sample $i ;\left(u_{i}, v_{i}, t_{i}\right)$ is the space-time geographic location of sample $i$ in space-time dimensions; and $u_{i}, v_{i}$, and $t_{i}$ are the longitude, latitude, and temporal coordinates, respectively. $\beta_{0}\left(u_{i}, v_{i}, t_{i}\right)$ is the intercept value, and $\beta_{k}\left(u_{i}, v_{i}, t_{i}\right)$ is the regression coefficient value of the $k$ th variable varying at TAZ I and time $t_{i}$. In light of the local weighted least-squares method, the estimated parameter can be calculated as follows:

$$
\hat{\beta_{k}}\left(u_{i}, v_{i}, t_{i}\right)=\left[X^{T} W\left(u_{i}, v_{i}, t_{i}\right) X\right]^{-1} X^{T} W\left(u_{i}, v_{i}, t_{i}\right) Y
$$

where $W\left(u_{i}, v_{i}, t_{i}\right)$ is a spatiotemporal weight matrix based on the Euclidean distance and Gaussian distance decay-based functions in the space-time domains. The diagonal elements of the weight matrix can be represented as:

$$
\mathrm{W}_{i j}^{S T}=\exp \left\{-\frac{\lambda\left[\left(u_{i}-u_{j}\right)^{2}+\left(v_{i}-v_{j}\right)^{2}\right]+\mu\left(t_{i}-t_{j}\right)^{2}}{h_{S T}^{2}}\right\}
$$

where location $\left(u_{i}, v_{i}\right)$ and $\left(u_{j}, v_{j}\right)$ are the central coordinates of the TAZ where samples $i$ and $j$ are located; $t_{i}$ and $t_{j}$ are the hour numbers for samples $i$ and $j$, respectively; $\lambda$ and $\mu$ are scale parameters to counterbalance the dissimilar effects since spatial distance and temporal distance are measured using dissimilar units; and $h_{S T}$ is the nonnegative parameter of the spatiotemporal bandwidth, which are calibrated and optimized through minimizing the Akaike information criterion (AIC).

The geographically weighted regression (GWR) model [68] is a simplified version of the GTWR model that embeds only the spatial dimension. The GWR model can be expressed as follows:

$$
Y_{i}=\beta_{0}\left(u_{i}, v_{i}\right)+\sum_{k=1}^{d} \beta_{k}\left(u_{i}, v_{i}\right) X_{i k}+\varepsilon_{i}
$$


where $\beta_{0}\left(u_{i}, v_{i}\right)$ is the intercept value, and $\beta_{k}\left(u_{i}, v_{i}\right)$ is the regression coefficient value of the $k$ th variable varying at TAZ $i$. The calculation process for GWR and GTWR was coded in MATLAB.

\subsection{Geographical Detectors (GDs)}

Geographical detectors are used to identify the influencing mechanisms of urban vibrancy and reveal the interactions among these influencing factors. Incorporating logical inference and statistical verification, the core idea of GDs is to detect the consistency of the spatial distribution pattern between dependent variable $Y$ and independent variable $X$ through spatial heterogeneity and to measure the explanatory degree of $X$ to $Y$ [69]. The power of determinant (PD) to the urban vibrancy effect (UV) is examined as follows:

$$
P D=1-\frac{\sum_{h=1}^{L} N N_{h} \sigma_{h}^{2}}{N \sigma^{2}}, h=1,2, \ldots, L
$$

where $P D$ is the explanatory power of factor $D$ on urban vibrancy; based on the spatially stratified heterogeneity of factor $D$, the whole region is classified into $L$ subregions, denoted by $h=1,2, \ldots, L$; $N_{h}$ and $N$ are the number of samples in the $h$ th subregion and the whole region, respectively; $\sigma_{h}^{2}$ and $\sigma^{2}$ are the divisional variations and global variance of the urban vibrancy in the $h$ th subregion and the whole region, respectively. The divisional variations $\sigma_{h}^{2}$ and the global variation $\sigma^{2}$ are denoted as follows:

$$
\begin{gathered}
\sigma_{h}^{2}=\frac{1}{N_{h}-1} \sum_{p=1}^{N_{h}}\left(Y_{h, p}-\overline{Y_{h}}\right)^{2} \\
\sigma^{2}=\frac{1}{N-1} \sum_{p=1}^{N}\left(Y_{p}-\bar{Y}\right)^{2}
\end{gathered}
$$

where $Y_{h, p}$ and $\overline{Y_{h}}$ are the value of the $p$ th sample and the average value of $Y$ in the $h$ th subregion, respectively; $Y_{p}$ and $\bar{Y}$ are the value of the $p$ th sample and the average value of $Y$ in the whole region, respectively.

The interaction detector is applied to detect the interaction among different factors $\left(X_{S}\right)$, that is, to assess the accountability of the combined effect (strengthening or weakening) and the respective effect on the urban vibrancy. First, the $P D$ values of two factors regarding urban vibrancy are computed $\left(P D\left(x_{1}\right)\right.$ and $\left.P D\left(x_{2}\right)\right)$. Then, $P D$ values with respect to the interaction between two factors are computed $\left(P D\left(x_{1} \cap x_{2}\right)\right)$ and compared with $P D\left(x_{1}\right)$ and $P D\left(x_{2}\right)$.

\section{Results and Discussion}

\subsection{Results of the GTWR Model}

\subsubsection{Model Comparison}

The spatial and temporal nonstationarities of the data should be tested before building the GTWR model. If the spatial and temporal nonstationarities are significant, then the GTWR model should be applied to explore the spatiotemporal influence of the urban morphology on vibrancy. As shown in Table 3, the results of Moran's I statistics illustrate the significant strong positive spatial autocorrelation for urban vibrancy and justify the considering of spatial nonstationarity. To gain an in-depth interpretation of how the relationship between urban morphology and urban vibrancy varies at different hours and in different regions, an analysis is based on the GTWR model for estimates with spatiotemporal variation.

Comparing diagnostic information with traditional models, GTWR is superior to OLS and GWR in terms of model fit and performance (Table 4). In particular, the significant increases of $R^{2}$ and the decrease of the sum of residual squares (RSS) indicate that GTWR has a better goodness of fit. The significant decrease of the Akaike information criteria (AIC) implies the much better performance of GTWR in exploring the relationships between the urban morphology and urban vibrancy. More importantly, the much lower Moran's I of residuals in GTWR suggests significant 
mitigation for the spatial autocorrelation. Given the spatial information and temporal information in the model, GTWR exhibits greater potential and a better interpretation.

Table 3. Spatial autocorrelation test using Moran's I.

\begin{tabular}{cccc}
\hline Model & Performance & On Weekday & On Weekend \\
\hline Spatial autocorrelation & Moran's $I$ & $\begin{array}{c}0.43^{* *} \\
(\mathrm{z}-\mathrm{score}=23.7)\end{array}$ & $\begin{array}{c}0.41^{* *} \\
(\mathrm{z}-\mathrm{score}=22.8)\end{array}$ \\
\hline
\end{tabular}

NOTE: ** significant at 0.01 level.

Table 4. Comparison of OLS, GWR, and GTWR based on model diagnostics.

\begin{tabular}{cccc}
\hline Model & Performance & On Weekday & On Weekend \\
\hline OLS & $R^{2}$ & 0.655 & 0.659 \\
& RSS & 3902 & 5234 \\
& AIC & -2593.5 & -2307.0 \\
& Moran's I of residuals & $0.15^{* *}$ & $0.16^{* *}$ \\
& & $(\mathrm{z}-\mathrm{score}=13.0)$ & $(\mathrm{z}$-score $=10.9)$ \\
\hline GWR & $R^{2}$ & 0.723 & 0.716 \\
& RSS & 3597 & 4575 \\
& AIC & -2120.3 & -2139.1 \\
& Moran's I of residuals & $0.09 * *$ & $0.09 *$ \\
& (z-score $=3.5)$ & $(\mathrm{z}$-score $=2.3)$ \\
\hline \multirow{2}{*}{ GTWR } & $R^{2}$ & 0.957 & 0.955 \\
& RSS & 1768 & 967 \\
& AIC & -1771.9 & -1891.1 \\
& Bandwidth & 0.2117 & 0.2889 \\
& Moran's I of residuals & $0.08^{*}$ & $0.07 *$ \\
& & $(\mathrm{z}$-score $=-1.1)$ & $(\mathrm{z}$-score $=-0.2)$ \\
\hline
\end{tabular}

NOTE: ** significant at 0.01 level, ${ }^{*}$ significant at 0.05 level.

Table 5. Descriptive statistics of the regression coefficients of Weekdays_GTWR.

\begin{tabular}{cccccccc}
\hline Variable & Avg & Min & Q1 & Q2 & Q3 & Max & Std \\
\hline Intercept & -0.230 & -19.727 & -0.455 & -0.095 & 0.264 & 11.920 & 1.824 \\
DRL & 0.088 & -5.473 & -0.132 & 0.093 & 0.318 & 7.966 & 0.634 \\
INCH & 0.112 & -2.227 & -0.168 & 0.008 & 0.187 & 86.913 & 2.622 \\
BuAR & 0.076 & -388.176 & -0.392 & 0.042 & 0.674 & 194.092 & 12.382 \\
BuCR & 0.213 & -11.668 & 0.029 & 0.211 & 0.385 & 3.576 & 0.555 \\
MixBuA & 0.085 & -12.116 & -0.055 & 0.056 & 0.213 & 6.752 & 0.554 \\
DBoN & -0.106 & -17.549 & -0.383 & -0.001 & 0.436 & 35.582 & 1.992 \\
DivPOI & 0.017 & -2.620 & -0.077 & 0.002 & 0.108 & 11.362 & 0.507 \\
CSPOI & 0.267 & -32.354 & -0.174 & 0.199 & 0.606 & 13.327 & 1.320 \\
ORPOI & 0.111 & -6.858 & -0.086 & 0.073 & 0.267 & 28.634 & 0.975 \\
ResPOI & 0.164 & -15.781 & -0.162 & 0.032 & 0.215 & 150.550 & 4.249 \\
TraPOI & 0.199 & -13.908 & -0.119 & 0.175 & 0.523 & 8.021 & 0.955 \\
WEPOI & -0.055 & -9.356 & -0.685 & -0.042 & 0.419 & 58.902 & 2.352 \\
\hline
\end{tabular}

As the effect of urban morphology on urban vibrancy varies by local region and time period, the output matrices of the GTWR estimations are massive. To address this issue, seven characteristic values, average value (Avg), minimum (Min), lower quartile (Q1), median (Q2), upper quartile (Q3), maximum (Max), and standard deviation (Std), were used for descriptive statistics of the regression coefficients. The estimated results of Weekdays_GTWR and Weekends_GTWR are shown in Tables 5 and 6, respectively. In general, during the weekdays and weekends, except for the DRL, DBoN, and WEPOI, the average coefficients of morphological variables are positive concerning the increment of activity intensity. For DBoN and WEPOI, the average coefficients are always negative, and their 
magnitudes are greater on weekends. It suggests TAZs with high densities of blocks number and working, and educational POIs will generally reduce vibrancy. In regard to DRL, the sign of the average coefficient is positive on weekdays, while it is negative on weekends. It is difficult to display the GTWR regression results in spatial and temporal dimensions at the same time, so we examined the temporal variation dimension and the spatial variation dimension separately.

Table 6. Descriptive statistics of the regression coefficients of Weekends_GTWR.

\begin{tabular}{cccccccc}
\hline Variable & Avg & Min & Q1 & Q2 & Q3 & Max & Std \\
\hline Intercept & -0.211 & -19.750 & -0.428 & -0.060 & 0.272 & 11.343 & 1.867 \\
DRL & -0.097 & -3.437 & -0.128 & 0.084 & 0.309 & 6.416 & 0.624 \\
INCH & 0.095 & -2.183 & -0.174 & 0.010 & 0.173 & 81.271 & 2.353 \\
BuAR & 0.183 & -308.807 & -0.311 & 0.144 & 0.809 & 197.753 & 11.047 \\
BuCR & 0.205 & -11.514 & 0.011 & 0.188 & 0.377 & 4.717 & 0.572 \\
MixBuA & 0.088 & -12.162 & -0.059 & 0.061 & 0.224 & 7.331 & 0.558 \\
DBoN & -0.156 & -19.331 & -0.402 & 0.002 & 0.361 & 35.297 & 2.024 \\
MixPOI & 0.013 & -2.776 & -0.078 & 0.005 & 0.100 & 11.404 & 0.515 \\
CSPOI & 0.351 & -25.388 & -0.121 & 0.322 & 0.705 & 10.661 & 1.258 \\
ORPOI & 0.138 & -4.832 & -0.080 & 0.093 & 0.313 & 22.888 & 0.917 \\
ResPOI & 0.180 & -10.799 & -0.152 & 0.049 & 0.228 & 120.600 & 3.723 \\
TraPOI & 0.210 & -10.917 & -0.128 & 0.183 & 0.531 & 7.844 & 0.942 \\
WEPOI & -0.226 & -9.738 & -0.871 & -0.130 & 0.255 & 84.025 & 3.001 \\
\hline
\end{tabular}

\subsubsection{Spatial Variability of Coefficients}

The estimation of local coefficients is one of the important characteristics of the GTWR model, which denotes spatial heterogeneity and is mappable for the local differences of metrics. By averaging the coefficients over $24 \mathrm{~h}$ extracted from the GTWR model results, the coefficients with different timestamps but the same TAZ-ID were aggregated into a single coefficient. Figure 5 delineates the spatially variable nature of the coefficients. The spatial variation pattern is colored according to regression coefficients. Red denotes a positive effect, blue indicates a negative effect, and the darker the color, the greater the degree. In this way, the enhancement or restraint of morphological metrics' influences on urban vibrancy can be observed intuitively. The coefficients of the same metric may have positive or negative discrepancies to varying magnitudes among the different TAZs. The distribution of spatial effects on weekdays and weekends follows roughly the same trend.
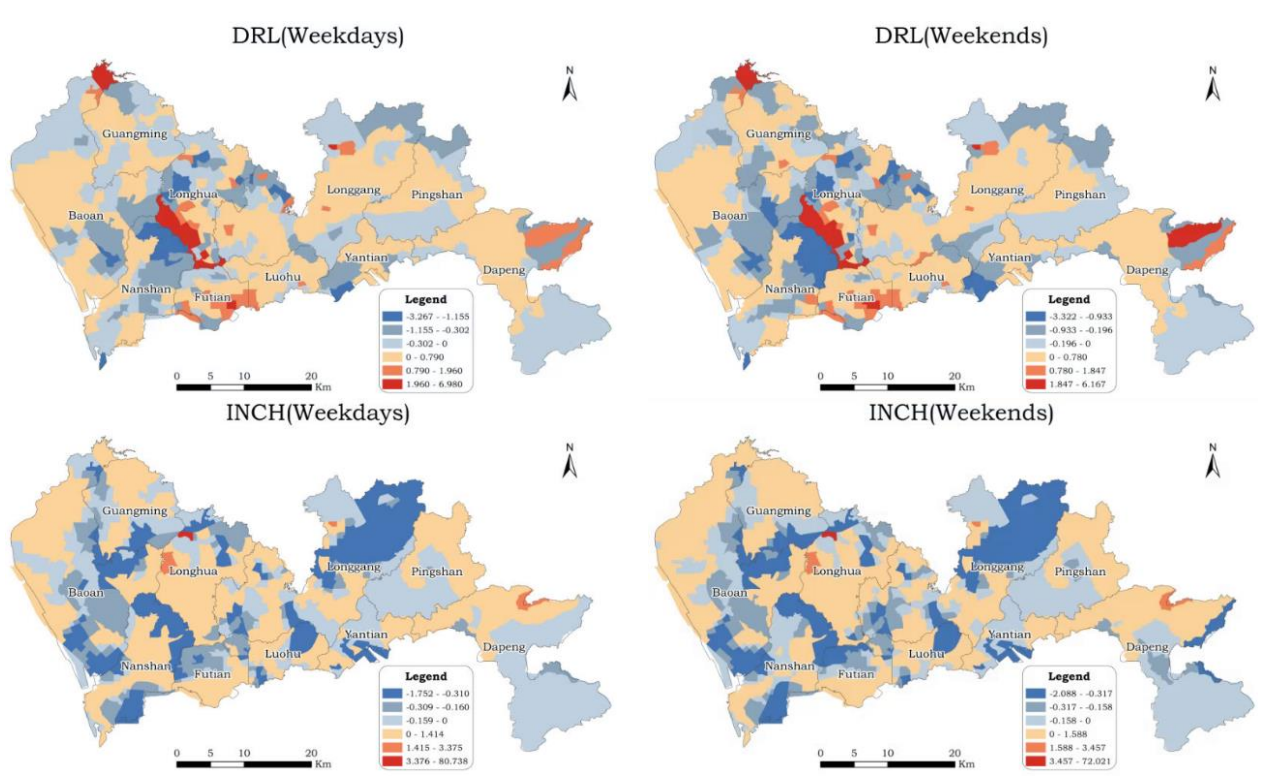

Figure 5. Cont. 

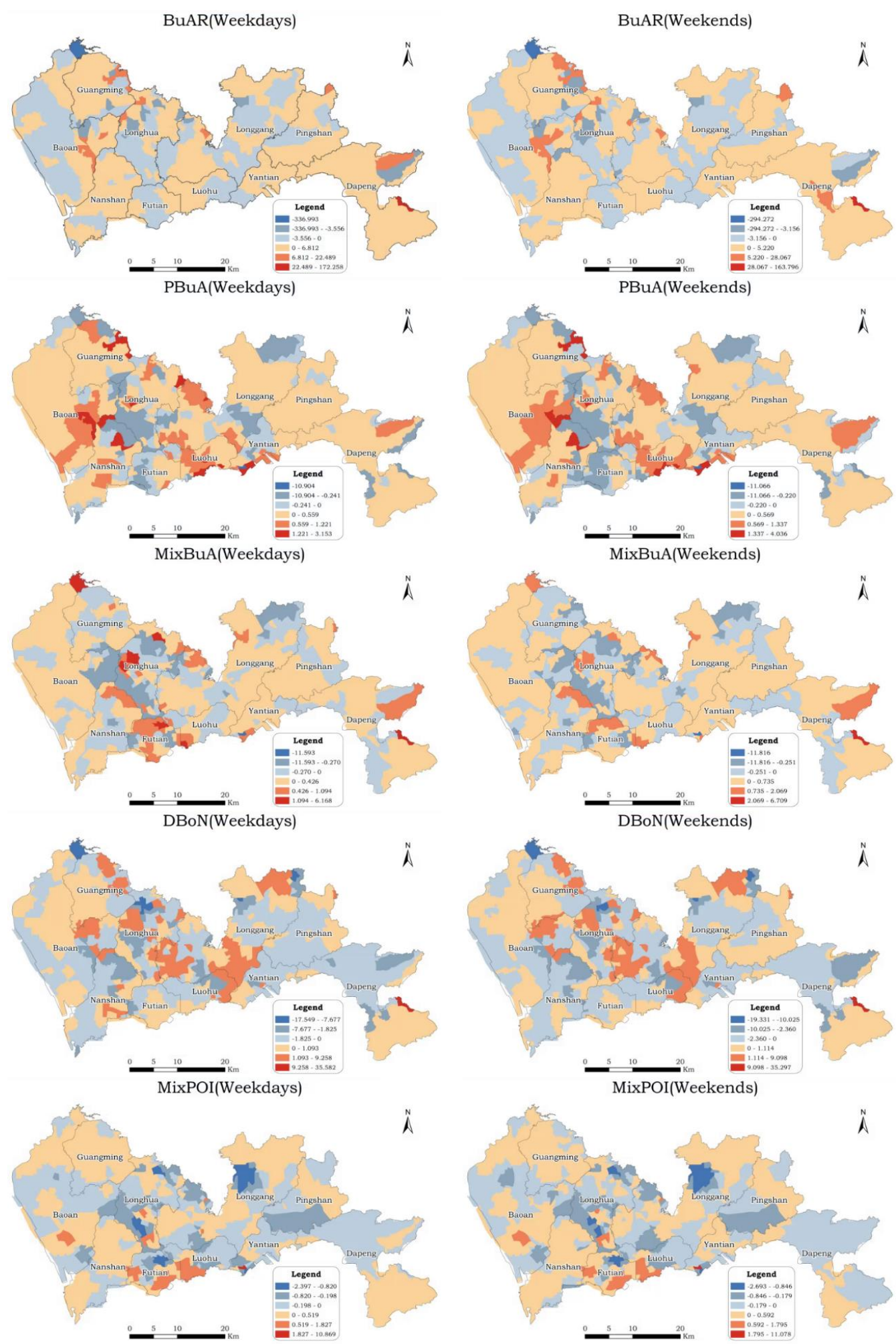

Figure 5. Cont. 

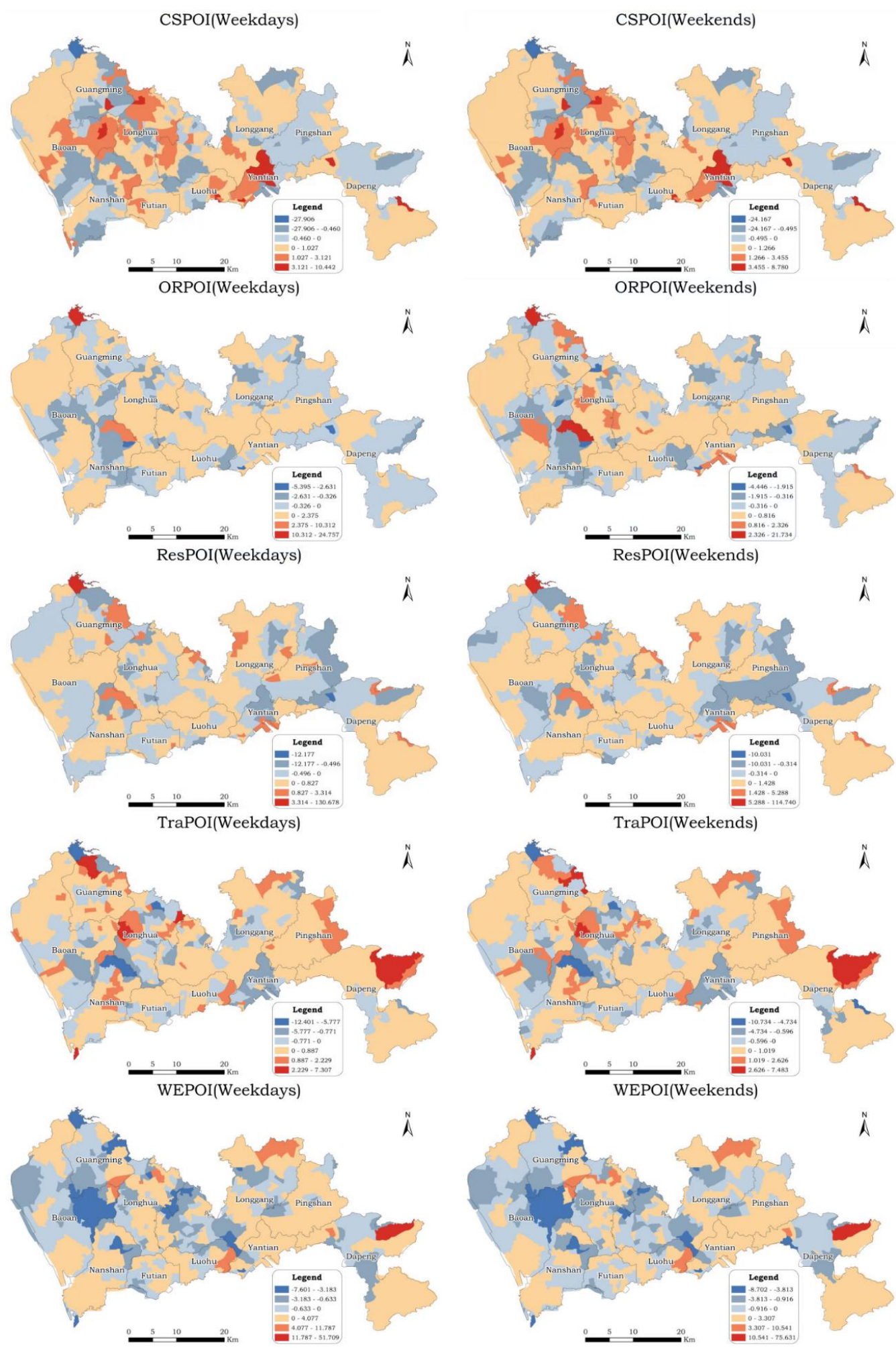

Figure 5. The spatial distribution of the coefficients.

In regard to Density of road length (DRL), the positive coefficients are mostly concentrated in city cores. The enhanced urban permeability brought about by dense road networks makes contact among the exterior and interior of the blocks relatively accessible. The frequent cultural, social, and economic activities associated with this road pattern are the source of vibrancy. In contrast, the impacts of DRL on urban vibrancy are negative in some areas near the boundary of the city and within the basic ecological control line, where urban activity and daily amenity are actually the minority. 
Integration-Choice degree (INCH) plays a positive role in increasing urban vibrancy in a broader noncore region. INCH represents the arrival and crossing potential of the road network; it reflects the degree of internal and external connectivity of a neighborhood. With urbanization, Shenzhen has attached great importance to the multicentric pattern of the urban development structure, which is emerging as an urban pattern with three axes, two belts, and multiple centers. The roads located in the development axes and belts have the mission to connect the multilevel centers, so the two potentials of the roads at these locations are equally important. This may partly explain why increasing the road potential of to-movement and through-movement here can inspire and retain human flow.

However, Building area ratio (BuAR) and Proportion of building area (BuCR) have positive influences on urban vibrancy in vast areas in Shenzhen, indicating their favorable effects on urban activities. These two metrics reflect the vertical and horizontal development intensity of urban space. Although TAZs with positive coefficients represent a slightly smaller proportion of all TAZs, the coefficient values of BuAR are notably larger. In contrast, the positive coefficients of BuCR, with smaller values, are distributed across most of the whole region. Because of the restrictions imposed on urban development in natural ecological control areas, most urban built-up areas of Shenzhen have accomplished horizontal high-density development. In the future, the high density of urban construction from a vertical perspective within restrained areas is the only way to promote sustainable development, and it comes as no surprise that BuAR more greatly affects the urban vibrancy in urban cores. Mix building Ages (MixBuA) has a positive association with vibrancy in the urban area, except in the few natural ecological control areas. Urban places with a mixture of building ages, accompanied by mixed building types, building sizes, and housing price or land rent, are preferable and affordable, not only for people at different income levels, but also for small and diverse enterprises.

The coefficients of Density of block number $(\mathrm{DBoN})$ are positive in the urban areas that are generally commercial-oriented and work-oriented and negative in the TAZs that are generally residential-oriented. The negative coefficients in the residential-oriented areas could be reasonable, because too-small blocks make it difficult to achieve distance from the pedestrian flow and traffic stream, resulting in noise and insecurity.

In most areas of Shenzhen, especially in the core areas, the coefficients of Commercial service (CSPOI) on urban vibrancy are positive. Therefore, CSPOI has vital influence in stimulating vibrancy in prosperous and important areas. The urban activities in the places of commerce and public services are abundant in quantity, variety, and persistence. Outdoor recreation (ORPOI) has positive influences on urban vibrancy in some areas around mountains or near lakes. On account of the natural ecological control areas, the total area of parks in Shenzhen city is $393.19 \mathrm{~km}^{2}$, including nature parks, city parks, and community parks, providing space for the outdoor activities of residents and visitors and promoting urban vibrancy for Shenzhen.

The coefficients of Work and education (WEPOI) are larger in Baoan, Longhua, Longgang, and Pingshan, showing that the influences of work or education activities are greater here than in other areas. According to the urban master plan, these areas are the focus of the Shenzhen industry cluster, which strongly affects the distribution of urban vibrancy. With cheaper land rent, less traffic congestion, and a more favorable work environment, suburbs centralize more industries and laborers. Simultaneously, spatial variations obviously differentiate WEPOI from ResPOI, which indicates the residential-working separation in the city. For Residence (ResPOI), TAZs with large values are situated throughout the city, in both the downtown and the suburbs. First, areas in the suburbs are typically around industrial parks, such as Guangming and Longgang. In addition, residences in the central area are in close proximity to hospitals, schools, and other amenities. Different demands result in residential buildings having an important influence across Shenzhen.

Transportation (TraPOI) has a positive effect in the central area of the transit network and tends to present a higher positive correlation with urban vibrancy when shifting away from the central area. Due to the well connection between rail part and bus part in the public transportation, it is convenient for people to travel from one place to another for social interactions. Data show that the 
public transportation ridership in Shenzhen is more than five million every day. With the gradual strengthening of the internal and external connectedness of the city, the construction of a traffic corridor connecting two cities in the bordering area can boost the vibrancy of the area. For MixPOI, the estimated coefficients with positive values are in the urban center and the subcenters of Futian, Luohu, Baoan, and Longhua. The notable regions are the high-tech zones and industrial zones in Nanshan and Longgang, where the DivPOI has negative influence. These results are incompatible with the previous findings that a higher mixture degree of urban functions can efficiently promote urban vibrancy. The reason for the phenomenon is that the detailed planning of the current control delineates some key functions in theses plot; these key functions, rather than others, are responsible for the crowds.

\subsubsection{Temporal Variability of Coefficients}

In contrast to global OLS models, GTWR models entail the significant advantage of the incorporation of the temporal dimension, which indicates temporal heterogeneity. On the basis of the GTWR model results, we averaged all TAZ units in space and generated a series of estimated coefficients that vary only temporally. Figure 6 describes the temporal variability of the coefficients. Blue lines represent the estimations for the weekday subsample; red lines are the estimations for the weekend subsample. The trends and degrees of variation in the time series exhibit the effects of regular and symmetric variation from low stability in the nighttime to high stability in the daytime or from high stability in the nighttime to low stability in the daytime. Slight deviations in peak hours and trough hours exist between weekdays and weekends, and the peaks and troughs of the coefficient curves appear slightly later on weekends than on weekdays. Moreover, the fluctuation amplitude of the coefficient curves is smaller on weekends than on weekdays.

Density of road length (DRL) and Integration-Choice (INCH) contribute positively to urban vibrancy all day long on weekdays and weekends. INCH is a combination of integration analysis and choice analysis that measures both the through-movement and to-movement potentials of road segments. On weekdays, the coefficients of DRL retain a high stable value during the night; by contrast, the effects of INCH on vibrancy become greater during the day. This suggests that a higher density of road networks and higher connectivity of the road network together promote a higher level of urban vibrancy throughout the working day. On the weekends, the two metrics have a comparably stable positive effect on the vibrancy of the city.

Three metrics related to buildings all have positive impacts on urban vibrancy on weekdays and weekends throughout the day. Building area ratio (BuAR) varies similarly over $24 \mathrm{~h}$ on different days of the week. Moreover, the influence of BuAR is greater on weekdays than on weekends. As one of the cities with the most skyscrapers in the world, Shenzhen has extensively developed the vertical structure of city space to accommodate more diverse and numerous human activities. On weekdays and weekends, the influence of Building cover ratio (BuCR) on the vibrancy of Shenzhen fluctuates slightly towards different directions during the day. Specifically, this metric reaches the maximum impact during working hours. This reflects the intensive aggregation of buildings in work areas, which suggests that building agglomeration (construction intensity) is of vital importance to urban development. Mix building age (MixBuA) has a consistently significant effect on urban vibrancy throughout the day and night, indicating that a greater mixture of old and new buildings is associated with a greater intensity of urban activity.

Density of block number (DBoN) significantly increases urban vibrancy during the day on working days and peaks at noon. At night and on weekends, the positive effects of DBoN are not apparent. When people are relaxing and recharging, whether at home or outside, enjoying tranquil and leisure moments becomes the top need.

MixPOI is positively and slightly correlated with urban vibrancy, which is attributed to the widespread advocacy of the idea of multifunctional integration in urban renewal in recent years. In this context, the specific functional composition is more critical than the functional mixture. POIs of 
various functions, except for WEPOI, positively affect urban vibrancy at all times of the day and all days of the week. The effect of WEPOI on vibrancy is positive during working hours and negative during nonworking hours, including weekday nights and weekends, which suggests that WEPOI can restrain urban vibrancy during nonworking hours. More concretely, on weekdays, WEPOI increases progressively in the morning, maintains a comparatively high value in the period of 11:00-16:00, and continues to decline steadily after peak hours until the end of the day. This result shows a typical variation in the theme of people's activities. For urbanites, work and business dominate working hours. People tend to engage in leisure and recreation activities in the evening and on weekends to release pressure and relieve fatigue. Taking into account the diversity and balance of urban functions in time, the city can be vigorous and prosperous at any time.

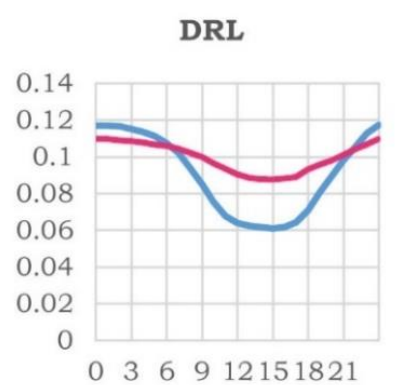

PBuA

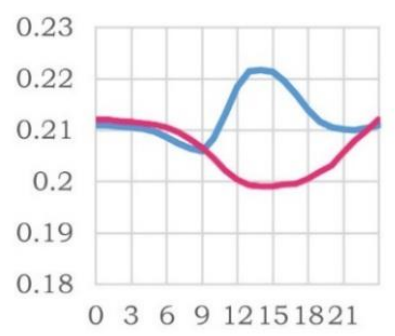

MixPOI

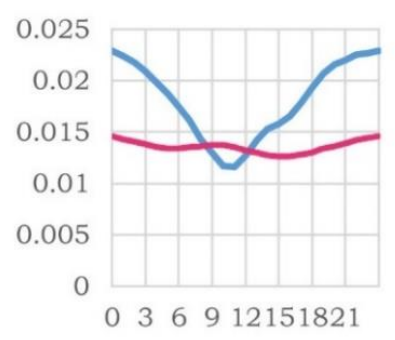

ResPOI

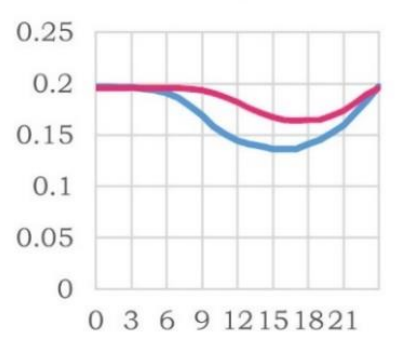

NACH

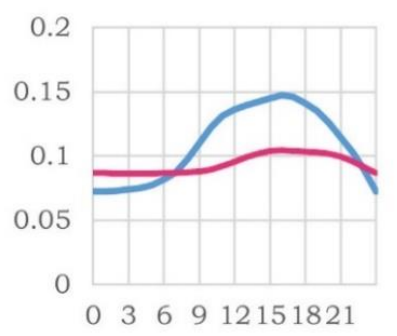

MixBuA

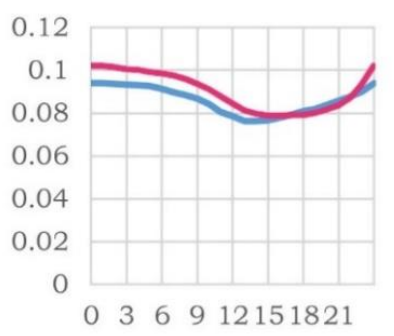

CSPOI

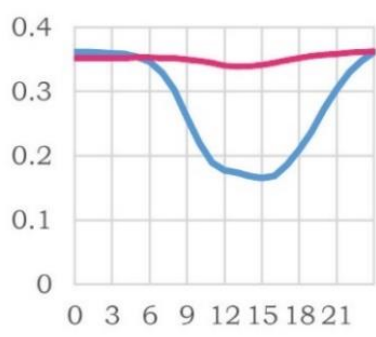

TraPOI

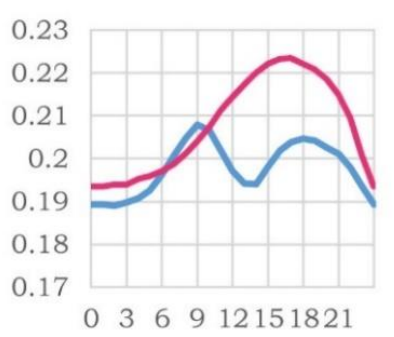

BuCR

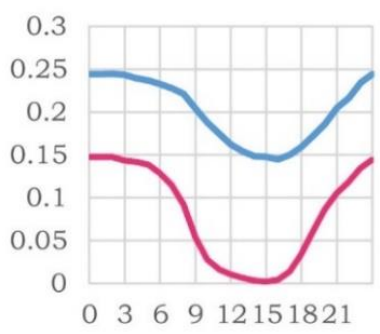

DBoN

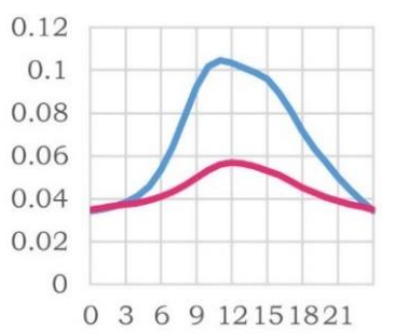

ORPOI

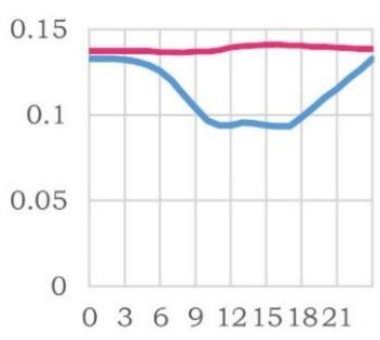

WEPOI

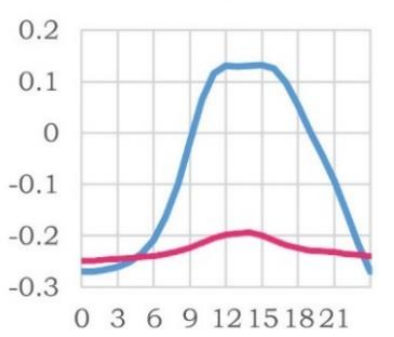

Figure 6. The temporal variability of the coefficients. Blue lines represent the estimations for the weekday subsample; red lines are the estimations for the weekend subsample.

Such a lifestyle is also reflected in the temporal characteristics of the influences of CSPOI and ORPOI on urban vibrancy. The effect of CSPOI is higher on weekends than on weekdays, in general; 
it is basically the equivalent over the weekend. Comparatively, the coefficient curve of CSPOI has a larger variation trend on weekdays, presenting an inverted U shape. ORPOI exhibits an analogous trend of impact on urban vibrancy but with less strength. When people engage in a wider range of urban activities during nonworking hours, the activity intensity of residents is more susceptible to CSPOI and ORPOI.

The overall trend of the impact of ResPOI on vibrancy is greater at night than during the day and is greater on weekends than on weekdays, reflecting the sleeping, working, and living patterns of Shenzhen residents to a certain extent. The continuing positive effects suggest that some people choose to work from home. The coefficient curve of TraPOI during the weekdays has a bimodal distribution corresponding to commuting characteristics, with peak values appearing at 9:00 and 18:00. During the weekend afternoon to evening, TraPOI shows greater potential to enhance urban vibrancy. According to a relevant report, Shenzhen ranked first in the national public transport service index rankings in 2017, with a well-designed connection between subways and buses. Therefore, TraPOI has a positive effect on improving vibrancy in the megacity.

\subsection{Results of the GD Model}

To identify the interactive or synergetic effect of different morphological metrics on urban vibrancy, interaction detection was adopted to determine whether accountability for vibrancy is strengthened or weakened or whether the impact of these metrics on vibrancy is independent. Because of the time-dependent effect of individual metrics on vibrancy, the interaction detector was examined in three periods (weekdays09-20, weekdays21-08, and weekends). The results show that morphological metrics have interactive effects on urban vibrancy. The synergetic effect of the morphological metrics is demonstrated as bivariate enhancement or nonlinear enhancement. Every morphological metric influences urban vibrancy co-dependently with the others. Table 7 lists all the metric pairs with the possibility to nonlinearly enhance the interactive influence on urban vibrancy in some periods.

Table 7. Results of the interaction detector analysis.

\begin{tabular}{cccc}
\hline & Weekdays09-20 & Weekdays21-08 & Weekends \\
\hline $\mathrm{DRL} \cap \mathrm{MixPOI}$ & $\mathbf{J}$ & $\mathbf{J}$ & $\mathbf{J}$ \\
$\mathrm{INCH} \cap \mathrm{MixPOI}$ & $\mathbf{J}$ & $\uparrow \uparrow$ & $\uparrow \uparrow$ \\
$\mathrm{BuAR} \cap \mathrm{MixPOI}$ & $\mathbf{J}$ & $\uparrow \uparrow$ & $\uparrow \uparrow$ \\
$\mathrm{BuCR} \cap \mathrm{MixPOI}$ & $\mathbf{J}$ & $\uparrow \uparrow$ & $\uparrow \uparrow$ \\
$\mathrm{MixBuA} \cap \mathrm{MixPOI}$ & $\mathbf{J}$ & $\mathbf{J}$ & $\mathbf{J}$ \\
$\mathrm{ORPOI} \cap \mathrm{MixPOI}$ & $\mathbf{J}$ & $\mathbf{J}$ & $\mathbf{J}$ \\
$\mathrm{Re} P O I \cap \mathrm{MixPOI}$ & $\mathbf{J}$ & $\mathbf{J}$ & $\mathbf{J}$ \\
TraPOI $\cap \mathrm{MixPOI}$ & $\mathbf{J}$ & $\uparrow \uparrow$ & $\uparrow \uparrow$ \\
\hline
\end{tabular}

NOTE: $\uparrow \uparrow$ denotes that the two metrics enhance each other; $\mathbf{J}$ denotes nonlinear enhancement of the two metrics.

The PD values of interactions between all morphological metrics are greater than the PD values of any individual metric, and the synergetic effect of morphological metrics is demonstrated as bivariate enhancement or nonlinear enhancement. In the daytime on weekdays, DRL, INCH, BuAR, BuCR, MixBuA, ORPOI, ResPOI, and TraPOI interact with MixPOI, thus producing nonlinear enhancement effects. In the nighttime of weekdays and on weekends, MixPOI interacts with DRL, MixBuA, ORPOI, and ResPOI, thus generating nonlinear enhancement effects. Generally, the effects of morphological metrics on urban vibrancy interact significantly with each other rather than acting independently. The interactive effect of two or more morphological metrics on urban vibrancy is not a direct summation of each part but rather a superposition with bivariate and nonlinear enhancement. 
Although MixPOI has a slight influence on urban vibrancy individually, it can collaborate with other metrics to strengthen the influences on urban vibrancy. The promotion effect of MixPOI on urban vibrancy does not lie in itself but in the synergistic effect with other morphological elements and morphological metrics. In all the functional metrics, only MixPOI cooperating with the formality metric exhibits a nonlinear enhanced effect on urban vibrancy. The notable synergetic effect of MixPOI and other functional metrics also indicates that it is impractical to discuss POI mixtures under the conditions without POI concentration. POI concentration satisfies the prosperity of urban areas for a period of time in a day; for example, ORPOI lets people enjoy their leisure time just for a while. The POI mixture contributes to urban vibrancy at any time of day. When the city maintains continuous and high vibrancy, it accomplishes the high-quality development of urban construction. MixPOI displays extraordinary synergy with most morphological metrics.

\subsection{Discussion}

Coupled with the increasing demands for livability, the creation, maintenance, and advancement of urban vibrancy are inevitable requirements for sustainable urban development. Shenzhen is one of the earliest urbanized, fastest urbanizing, and most urbanized metropolises in China; it is a representative example experiencing the most significant development. Shenzhen was chosen to explore the association between urban morphology and vibrancy at the fine scale in a big data environment. This study offers three major contributions.

The first contribution of our work is the formulation of the explicit FormFun model for urban morphology description. With the aid of extensive application of big and open data, urban vibrancy advancement at a fine scale and with pragmatic metrics emerges for effective implementation of people-oriented sustainable urban development. The metrics in the model are selected on the theoretical and empirical basis, and the spatial scales in our study are the neighborhood (TAZ). We selected 12 metrics in two dimensions and four elements to establish the FormFun framework. A rational metric system was established that emphasizes the pattern of urban functionality (POI) as a part of urban morphology. Neighborhoods with good formality are inclined to substantial internal and external contact; neighborhoods with sufficient functionality are capable of extending the stopover time. The adjustment and extension of the FormFun model can be further used to accommodate the different urbanization phase and spatial scales, such as the metrics of road level and POI size. The other multifaceted and comprehensive urban concepts—innovation and resilience-can also be investigated using the model.

The second contribution lies in the exploration of the effect of urban morphology on urban vibrancy using GTWR for the spatiotemporal part and GDs for the synergetic part. Urban morphology has spatiotemporally heterogeneous effects on vibrancy according to the results by GTWR. The impact of the same metric on urban vibrancy varies in different local regions and time periods. Empirical evidence continues to confirm that vibrant cities are equipped with dense street networks, small and medium blocks, and diversification and intensification of building and land use. Under the premise of adapting to local conditions, urban spaces combine multiple morphological metrics for the accomplishment of a full-region and all-time vibrancy. The results of the GD model suggest that morphological indices synergistically promote urban vibrancy. The synergetic effect is demonstrated as bivariate enhancement or nonlinear enhancement. The mixture of urban functions is worthy of attention because of its extraordinary synergy. In general, urban designers and planners should not only consider certain morphological elements and features, but also comprehensively investigate the vibrancy level and spatiotemporal characteristics of different locations, as well as the functional orientation and development history of urban areas. Integrating spatiotemporal influence mechanism and synergistic influence mechanism contributes to corresponding creation and promotion strategies to carry out targeted local optimization and overall improvement of vibrancy.

The third contribution is the comprehensive analysis of the relationships between vibrancy and morphology, choosing Shenzhen as an example. China has the most megacities worldwide and will 
have eight megacities by 2030. However, people-oriented sustainable urban development is confronted with prominent challenges in the unprecedented urbanization process. We chose Shenzhen as the case study area due to its geographical and strategic position in China. The urban structure of Shenzhen is profoundly multicentric, with three axes, two belts, and multiple centers of urban vibrancy. It is highly livable, inclusive, intensive, and sustainable in the context of a dense population, diverse material needs, and spiritual pursuits. Therefore, the experiences from Shenzhen provide reference for the creation, maintenance, and advancement of a vigorous and prosperous city.

However, this study has several limitations that should be considered in follow-up work. First, exploring the impact of individual factors (e.g., age, gender, socioeconomic conditions, and so on) on urban vibrancy as well as the impact of factors such as behavioral willingness and environmental perception is difficult with the mobile phone positioning data. Additionally, the FormFun model considers only the individual indices without considering the integrated index. In future research, we will be combining sociodemographic features to identify overall morphological characteristics of the most dynamic and least dynamic urban areas in the city to reconstruct the urban morphology.

\section{Conclusions}

In this study, we examined the spatiotemporal and synergetic influences of morphological metrics on urban vibrancy in Shenzhen using the GTWR model and geographic detectors. We proposed the FormFun model to decompose urban morphology into two dimensions (formality and functionality) and four elements (road, block, building, POI). The results prove the following: (1) Dense street networks, small and medium blocks, and diversification and intensification of building and land use are beneficial to urban vibrancy. (2) Urban morphology has a spatiotemporally heterogeneous effect on vibrancy. Under the premise of adapting to local conditions, urban spaces can combine multiple morphological metrics for the accomplishment of a full-region and all-time vibrancy. (3) The interaction of two morphological metrics enhances the effect of each individual morphological metric, and the mixture of urban function is worthy of attention in planning practices because of its extraordinary synergy, not its capacity. From the perspective of local optimization and overall improvement, the conclusion provides ideas for the ongoing urban renewal in China and other megacities around the world.

Author Contributions: The research was mainly conceived and designed by S.L. and C.W. Y.L. collected and processing the data. C.W. finished the programming. S.L. performed the experiments and drafted the manuscript. Z.L. visualized formal analysis. Q.D. reviewed the manuscript and provided comments. All authors have read and agreed to the published version of the manuscript.

Funding: This research was funded by the National Key Research and Development Program of China (2016 YFC 0803106), the National Natural Science Foundation of China (Project No. 41571438 and No. 41901326), and the Natural Science Foundation of Jiangsu Province (BK20190742).

Conflicts of Interest: The authors declare no conflict of interest affects the work reported in this paper.

\section{References}

1. UNDESA. World Urbanization Prospects 2018: Highlights; United Nations, Department of Economic and Social Affairs, Population Division. Available online: https://population.un.org/wup/Publications/ (accessed on 11 June 2020).

2. Krueger, R.; Buckingham, S. Towards a 'consensual' urban politics? Creative planning, urban sustainability and regional development. Int. J. Urban Reg. Res. 2012, 36, 486-503. [CrossRef]

3. Montgomery, J. Making a city: Urbanity, vitality and urban design. J. Urban Des. 1998, 3, 93-116. [CrossRef]

4. Landry, B. Race, Gender and Class: Theory and Methods of Analysis; Routledge: New York, NY, USA, 2016.

5. Dale, A.; Ling, C.; Newman, L. Community vitality: The role of community-level resilience adaptation and innovation in sustainable development. Sustainability 2010, 2, 215-231. [CrossRef]

6. Li, M.; Shen, Z.; Hao, X. Revealing the relationship between spatio-temporal distribution of population and urban function with social media data. GeoJournal 2016, 81, 919-935. [CrossRef] 
7. Jacobs, J. The Death and Life of Great American Cities; Random House: New York, NY, USA, 1961.

8. Lynch, K. Good City Form; MIT Press: Cambridge, MA, USA, 1984.

9. Van Lenthe, F.J.; Brug, J.; Mackenbach, J.P. Neighborhood inequalities in physical inactivity: The role of neighborhood attractiveness, proximity to local facilities and safety in The Netherlands. Soc. Sci. Med. 2005, 60, 763-775. [CrossRef] [PubMed]

10. Jin, X.; Long, Y.; Sun, W.; Lu, Y.; Yang, X.; Tang, J. Evaluating cities' vitality and identifying ghost cities in China with emerging geographical data. Cities 2017, 63, 98-109. [CrossRef]

11. Krier, L. The Architecture of Community; Island Press: Washington, DC, USA, 2009.

12. Brenner, N. Implosions/Explosions: Towards a Study of Planetary Urbanization; Jovis: Berlin, Germany, 2014.

13. Woodworth, M.D.; Wallace, J.L. Seeing ghosts: Parsing China's "ghost city" controversy. Urban Geogr. 2017, 38, 1270-1281. [CrossRef]

14. Oliveira, V.; Medeiros, V. Morpho: Combining morphological measures. Environ. Plan. Plan. Des. 2016, 43, 805-825. [CrossRef]

15. Ye, Y.; Yeh, A.; Zhuang, Y.; Van Nes, A.; Liu, J. “Form syntax" as a contribution to geodesign: A morphological tool for urbanity-making in urban design. Urban Des. Int. 2017, 22, 73-90. [CrossRef]

16. Ravenscroft, N. The vitality and viability of town centres. Urban Stud. 2000, 37, 2533-2549. [CrossRef]

17. Zarin, S.Z.; Niroomand, M.; Heidari, A.A. Physical and social aspects of vitality case study: Traditional street and modern street in Tehran. Procedia Soc. Behav. Sci. 2015, 170, 659-668. [CrossRef]

18. Conzen, M.R.G. Alnwick, Northumberland: A study in town-plan analysis. Trans. Pap. (Inst. Br. Geogr.) 1960, 27, 1-122. [CrossRef]

19. Conzen, M.P. The study of urban form in the United States. Urban Morphol. 2001, 5, 3-14.

20. Maas, P.R. Towards a Theory of Urban Vitality; University of British Columbia: Vancouver, BC, Canada, 1984.

21. Nicodemus, A.G. Fuzzy vibrancy: Creative placemaking as ascendant US cultural policy. Cult. Trends 2013, 22, 213-222. [CrossRef]

22. Winters, M.; Brauer, M.; Setton, E.M.; Teschke, K. Built environment influences on healthy transportation choices: Bicycling versus driving. J. Urban Health 2010, 87, 969-993. [CrossRef]

23. Stern, M.J.; Seifert, S.C. Cultural clusters: The implications of cultural assets agglomeration for neighborhood revitalization. J. Plan. Educ. Res. 2010, 29, 262-279. [CrossRef]

24. Braun, L.M.; Malizia, E. Downtown vibrancy influences public health and safety outcomes in urban counties. J. Transp. Health 2015, 2, 540-548. [CrossRef]

25. Barreca, A.; Curto, R.; Rolando, D. Urban Vibrancy: An Emerging Factor that Spatially Influences the Real Estate Market. Sustainability 2020, 12, 346. [CrossRef]

26. De Nadai, M.; Staiano, J.; Larcher, R.; Sebe, N.; Quercia, D.; Lepri, B. The Death and Life of Great Italian Cities: A Mobile Phone Data Perspective. In Proceedings of the International World Wide Web Conferences Steering Committee, Montréal, QC, Canada, 11-15 April 2016; pp. 413-423.

27. Yue, Y.; Zhuang, Y.; Yeh, A.G.O.; Xie, J.-Y.; Ma, C.-L.; Li, Q.-Q. Measurements of POI-based mixed use and their relationships with neighborhood vibrancy. Int. J. Geogr. Inf. Sci. 2017, 31, 658-675. [CrossRef]

28. Wu, J.; Ta, N.; Song, Y.; Lin, J.; Chai, Y. Urban form breeds neighborhood vibrancy: A case study using a GPS-based activity survey in suburban Beijing. Cities 2018, 74, 100-108. [CrossRef]

29. Long, Y.; Huang, C. Does block size matter? The impact of urban design on economic vitality for Chinese cities. Environ. Plan. Urban Anal. City Sci. 2019, 46, 406-422. [CrossRef]

30. Sulis, P.; Manley, E.; Zhong, C.; Batty, M. Using mobility data as proxy for measuring urban vitality. J. Spat. Inf. Sci. 2018, 16, 137-162. [CrossRef]

31. Kim, Y.-L. Seoul's Wi-Fi hotspots: Wi-Fi access points as an indicator of urban vitality. Comput. Environ. Urban Syst. 2018, 72, 13-24. [CrossRef]

32. Ye, Y.; Li, D.; Liu, X. How block density and typology affect urban vitality: An exploratory analysis in Shenzhen, China. Urban Geogr. 2018, 39, 631-652. [CrossRef]

33. Larkham, P.J.; Jones, A.N. A Glossary of Urban Form; Institute of British Geographers: London, UK, 1991.

34. Oliveira, V. Urban Morphology: An Introduction to the Study of the Physical Form of Cities; Springer International Publishing: Cham, Switzerland, 2016.

35. Meng, Y.; Xing, H. Exploring the relationship between landscape characteristics and urban vibrancy: A case study using morphology and review data. Cities 2019, 95, 102389. [CrossRef] 
36. Zhang, A.; Li, W.; Wu, J.; Lin, J.; Chu, J.; Xia, C. How can the urban landscape affect urban vitality at the street block level? A case study of 15 metropolises in China. Environ. Plan. 2020. [CrossRef]

37. Katz, P.; Scully, V.J.; Bressi, T.W. The New Urbanism: Toward an Architecture of Community; McGraw-Hill: New York, NY, USA, 1994.

38. Gehl, J. New City Spaces; Danish Architectural Press: Copenhagen, Denmark, 2000.

39. Smith, T.; Nelischer, M.; Perkins, N. Quality of an urban community: A framework for understanding the relationship between quality and physical form. Landsc. Urban Plan. 1997, 39, 229-241. [CrossRef]

40. Cybriwsky, R. Changing patterns of urban public space: Observations and assessments from the Tokyo and New York metropolitan areas. Cities 1999, 16, 223-231. [CrossRef]

41. Filion, P.; Hammond, K. Neighbourhood land use and performance: The evolution of neighbourhood morphology over the 20th century. Environ. Urban Plan. Plan. Des. 2003, 30, 271-296. [CrossRef]

42. Sung, H.; Go, D.; Choi, C. Evidence of Jacobs's street life in the great Seoul city: Identifying the association of physical environment with walking activity on streets. Cities 2013, 35, 164-173. [CrossRef]

43. Kooshki, F.; Mollatabar, A.; Masumi, L. The local community planning (case study: Narmak neighborhood of Tehran). Int. J. Acad. Res. Bus. Soc. Sci. 2015, 5, 171-178. [CrossRef]

44. Zeng, C.; Song, Y.; He, Q.; Shen, F. Spatially explicit assessment on urban vitality: Case studies in Chicago and Wuhan. Sustain. Cities Soc. 2018, 40, 296-306. [CrossRef]

45. Mouratidis, K. Built environment and social well-being: How does urban form affect social life and personal relationships? Cities 2018, 74, 7-20. [CrossRef]

46. Delclòs-Alióa, X.; Gutiérrezc, A.; Miralles-Guasch, C. The urban vitality conditions of Jane Jacobs in Barcelona: Residential and smartphone-based tracking measurements of the built environment in a Mediterranean metropolis. Cities 2019, 86, 220-228. [CrossRef]

47. Xia, C.; Yeh, A.G.O.; Zhang, A. Analyzing spatial relationships between urban land use intensity and urban vitality at street block level: A case study of five Chinese megacities. Landsc. Urban Plan. 2020, 193, 103669. [CrossRef]

48. Wu, C.; Ye, X.; Ren, F.; Du, Q. Check-in behaviour and spatio-temporal vibrancy: An exploratory analysis in Shenzhen, China. Cities 2018, 77, 104-116. [CrossRef]

49. Goodchild, M.F. Prospects for a space-time GIS. Annu. Assoc. Am. Geogr. 2013, 103, 1072-1077. [CrossRef]

50. Sung, H.; Lee, S.; Cheon, S.H. Operationalizing Jane Jacobs's Urban Design Theory: Empirical Verification from the Great City of Seoul, Korea. J. Plan. Educ. Res. 2015, 35, 117-130. [CrossRef]

51. Wu, W.; Niu, X. Influence of Built Environment on Urban Vitality: Case Study of Shanghai Using Mobile Phone Location Data. J. Urban Plan. Dev. 2019, 145, 04019007. [CrossRef]

52. Tang, L.; Lin, Y.; Li, S.; Li, S.; Li, J.; Ren, F.; Wu, C. Exploring the Influence of Urban Form on Urban Vibrancy in Shenzhen Based on Mobile Phone Data. Sustainability 2018, 10, 4565. [CrossRef]

53. Lu, S.; Shi, C.; Yang, X. Impacts of Built Environment on Urban Vitality: Regression Analyses of Beijing and Chengdu, China. Int. J. Environ. Res. Public Health 2019, 16, 4592. [CrossRef]

54. Wu, H.; Jiao, H.; Yu, Y.; Li, Z.; Peng, Z.; Liu, L.; Zeng, Z. Influence Factors and Regression Model of Urban Housing Prices Based on Internet Open Access Data. Sustainability 2018, 10, 1676. [CrossRef]

55. Tan, R.; He, Q.; Zhou, K.; Xie, P. The effect of new metro stations on local land use and housing prices: The case of Wuhan, China. J. Transp. Geogr. 2019, 79, 102488. [CrossRef]

56. Hillier, W.R.G.; Yang, T.; Turner, A. Advancing DepthMap to advance our understanding of cities: Comparing streets and cities and streets with cities. In Proceedings of the Eighth International Space Syntax Symposium, Santiago, Chile, 3-6 January 2012.

57. Hillier, B. Spatial Sustainability in Cities: Organic Patterns and Sustainable Forms; Royal Institute of Technology (KTH): Stockholm, Sweden, 2009.

58. Chiaradia, A.; Hillier, B.; Schwander, C.; Barnes, Y. Compositional and urban form effects on residential property value patterns in Greater London. Proc. Inst. Civ. Eng. Urban Des. Plan. 2013, 166, 176-199. [CrossRef]

59. Yang, T.; Li, M.; Shen, Z. Between morphology and function: How syntactic centers of the Beijing city are defined. J. Urban Manag. 2015, 4, 125-134. [CrossRef]

60. Stonor, T. Measuring Intensity-Describing and Analysing the "Urban Buzz". Iconarp Int. J. Archit. Plan. 2015, 7, 240-248. [CrossRef] 
61. Serra, M.; Hillier, B. Angular and metric distance in road network analysis: A nationwide correlation study. Comput. Environ. Urban Syst. 2019, 74, 194-207. [CrossRef]

62. Shen, Y.; Karimi, K.; Law, S.; Zhong, C. Physical co-presence intensity: Measuring dynamic face-to-face interaction potential in public space using social media check-in records. PLoS ONE 2019, 14, e0212004. [CrossRef]

63. Hillier, B.; Iida, S. Network and psychological effects in urban movement. In International Conference on Spatial Information Theory; Springer: Berlin/Heidelberg Germany, 2005; pp. 475-490.

64. Turner, A. Angular analysis. In Proceedings of the 3rd International Symposium on Space Syntax; Georgia Institute of Technology: Atlanta, GA, USA, May 2001; pp. 30.1-30.11.

65. Moudon, A.V.; Lee, C.; Cheadle, A.D.; Garvin, C.; Johnson, D.; Schmid, T.L.; Lin, L. Operational definitions of walkable neighborhood: Theoretical and empirical insights. J. Phys. Act. Health 2006, 3, S99-S117. [CrossRef]

66. Huang, B.; Wu, B.; Barry, M. Geographically and temporally weighted regression for modeling spatio-temporal variation in house prices. Int. J. Geogr. Inf. Sci. 2010, 24, 383-401. [CrossRef]

67. Wu, C.; Ren, F.; Hu, W.; Du, Q. Multiscale geographically and temporally weighted regression: Exploring the spatiotemporal determinants of housing prices. Int. J. Geogr. Inf. Sci. 2019, 33, 489-511. [CrossRef]

68. Fotheringham, A.S.; Brunsdon, C.; Charlton, M. Geographically Weighted Regression: The Analysis of Spatially Varying Relationships; Wiley: New York, NY, USA, 2003.

69. Wang, J.F.; Li, X.H.; Christakos, G.; Liao, Y.L.; Zhang, T.; Gu, X.; Zheng, X.Y. Geographical Detectors-Based Health Risk Assessment and its application in the neural tube defects study of the Heshun Region, China. Int. J. Geogr. Inf. Sci. 2010, 24, 107-127. [CrossRef]

(C) 2020 by the authors. Licensee MDPI, Basel, Switzerland. This article is an open access article distributed under the terms and conditions of the Creative Commons Attribution (CC BY) license (http://creativecommons.org/licenses/by/4.0/). 